\title{
Use of weather forecast for increasing the self-consumption rate of home solar systems: an Italian case study
}

\author{
Mario Petrollese*, Giorgio Cau, Daniele Cocco \\ Department of Mechanical, Chemical and Materials Engineering, University of Cagliari, Via Marengo, 2 \\ 09123 Cagliari, Italy. \\ * Corresponding Author: Mario Petrollese \\ petrollese@unica.it, Tel. ++390706755741 Fax. ++390706755717
}

\begin{abstract}
With the aim of increasing the self-consumption rate of grid-connected Photovoltaic (PV) home systems, two main options can be implemented: the inclusion of an energy storage system, in particular a battery bank, and the adoption of a Demand Side Management (DSM) strategy. However, both the reshaping of the load consumption curve with the displacement of deferrable loads and the optimal management of the battery bank require estimation of the daily PV generation profile. The assessment of the on-site energy production can be carried out based on weather forecast data. However, the latter are characterized by uncertainty, which may affect the achievable self-consumption rate.

This work investigates the influence of weather forecast errors on the performance of home PV systems equipped with a battery bank and characterized by a certain share of deferrable loads. Two different weather forecast services are considered, referring to the annual meteorological conditions occurring in Rome, and energy consumption data for 150 different households are analysed. The self-consumption rate is maximized by solving a suitable optimization problem, while different combinations of relative battery capacity, PV-toload ratio, and share of deferrable loads are considered. Two different approaches-deterministic and stochastic - are adopted and compared with an ideal approach where the PV generation profile is perfectly forecasted. The results show that the adoption of the deterministic approach leads to a reduction in the achievable self-consumption rate in the range of $0.5-4.5 \%$ compared to the ideal approach. The adoption of a stochastic approach further reduces the deviations from the ideal case, especially in the case of consumption profiles with a high share of deferrable loads. Finally, a preliminary economic analysis proves that the use of a battery bank is not yet a cost-effective solution and a price reduction of the current battery prices is therefore required.
\end{abstract}

\section{Introduction}

After coal, Renewable Energy Sources (RESs) are the second-largest contributor to global electricity production, accounting for $22.6 \%$ of world generation in 2014 [1]. 


\begin{tabular}{|c|c|c|c|}
\hline \multicolumn{4}{|c|}{ NOMENCLATURE } \\
\hline \multicolumn{2}{|c|}{ Symbols } & \multicolumn{2}{|c|}{ Superscript } \\
\hline A & Area $\left[m^{2}\right]$ & B & Battery \\
\hline BCR & Benefit-cost ratio & $\mathrm{BC}$ & Battery charging phase \\
\hline DLR & Deferrable load ratio [\%] & $\mathrm{BD}$ & Battery discharging phase \\
\hline E & Energy [kWh] & DIR & Directly consumed \\
\hline GI & Global irradiance $\left[\mathrm{kW} / \mathrm{m}^{2}\right]$ & DL & Deferrable load \\
\hline I & Investment cost [€] & INV & Inverter \\
\hline $\mathrm{L}$ & Lifetime [year] & NDL & Non-deferrable load \\
\hline$P$ & Power output $[\mathrm{kW}]$ & PUR & Purchasing \\
\hline $\mathrm{R}_{\mathrm{B}}$ & Relative battery size & SEL & Selling \\
\hline $\mathrm{R}_{\mathrm{PV}}$ & PV-to-load ratio & $\mathrm{TL}$ & Total load \\
\hline SCR & Self-consumption rate & \multicolumn{2}{|c|}{ Acronyms } \\
\hline SSR & Self-sufficiency rate & $\mathrm{D}$ & Deterministic approach \\
\hline $\mathrm{T}$ & Temperature $\left[{ }^{\circ} \mathrm{C}\right]$ & DSM & Demand side management \\
\hline c & Specific cost $[€ / \mathrm{kWh}]$ & GHI & Global horizontal irradiance \\
\hline$f^{P V}$ & Derating factor & MAE & Mean absolute error \\
\hline $\mathrm{i}$ & Interest rate & MBE & Mean bias error \\
\hline$n^{P V}$ & Number of installed PV sub-arrays & MILP & Mixed integer linear programming \\
\hline$\Delta \mathrm{SCR}$ & Mean deviation of the self-consumption rate & NWP & Numerical weather prediction \\
\hline$\Delta t$ & Time step [h] & $\mathrm{PV}$ & Photovoltaic \\
\hline$\eta$ & Efficiency & RES & Renewable energy source \\
\hline \multicolumn{2}{|c|}{ Subscript (index) } & RMSE & Root mean square error \\
\hline $\mathrm{t}, \mathrm{T}$ & Time index and set & S & Stochastic approach \\
\hline \multirow[t]{2}{*}{$1, \mathrm{~L}$} & Load profile index and set & SOC & State of charge \\
\hline & & WFS & Weather forecast service \\
\hline
\end{tabular}

Solar Photovoltaic (PV) is one of the main renewable technologies and is experiencing very high annual growth rates in terms of installed capacity, which increases from 38 GW in 2010 [2] to 176 GW in 2014 [1] in OECD countries. A particular rise in the PV capacity has occurred in Italy, where the installed PV capacity achieved 18.9 GW at the end of 2015 [3], allowing Italy to become the third largest producers of PV electricity (25.2 TWh) in OECD countries, after Germany (38.4 TWh) and Japan (36 TWh) [4]. Still referring to the Italian situation, about $91 \%$ of PV systems have a peak power lower than $20 \mathrm{~kW}$, corresponding to about $20 \%$ of the overall Italian PV capacity [3]. Therefore, an increasing number of PV owners use the produced electricity directly to supply a share of their own consumption (the so-called prosumers). The interest in self-consumption of PV electricity is particularly noticeable for these prosumers, due to the economic advantages coming from the reduction in the amount of electricity purchased from the grid as well as the support policies introduced in several countries (in particular, with net-metering schemes) [5]. 
The improvement of the self-consumption in residential PV systems is mainly achieved by considering two options: the introduction of an energy storage system and the adoption of a Demand Side Management (DSM) strategy. These two methods have been well studied in the literature, as reported in an extensive review concerning self-consumption of PV electricity in buildings by Luthander et al. [6]. Among the alternative storage systems, battery storage (intended as both stationary systems and electric vehicles) is the most mature technology and the most suitable option for short-term energy storage [7]. Hoppmann et al. [8] demonstrated that given an economically rational household, investments in lead-acid battery storage are already profitable for some small residential PV systems. The achievable self-consumption in PV/battery systems depends on several relevant factors, such as the system design, location, and number of buildings involved. For instance, Merei et al. [9] analysed the self-consumption and degree of self-sufficiency in commercial buildings for several sizes of PV plant and battery bank. In [10], the self-consumption of residential PV power in a community of several single-family houses was evaluated by considering different battery capacities. In [11], the best configuration in terms of minimization of the energy cost for a given self-sufficiency rate was investigated by varying the PV power output and the storage capacity. In addition, an analysis on the effect on the grid was carried out. Linssen et al. [12] highlighted the major impact of the chosen load profile on the congruence between electricity demand and PV generation and hence on the share of self-consumption. Therefore, they recommended the use of realistic load profiles for modelling, system design, and battery selection instead of aggregated profiles (e.g. standard load profiles). For this reason, recent papers analysed the level of self-consumption for a large number of different household consumption profiles. For instance, Quoilin et al. [13] built up a database of load profiles from monitoring data. The authors stated that the selfconsumption rate largely varies between households and, therefore, the level of self-consumption cannot be predicted in a deterministic way. This fact was proved by Nyholm et al. [14], who investigated the optimal sizing of battery and PV modules by using real household energy consumption data from 2104 Swedish dwellings. The results highlighted an important dispersion in the achievable self-consumption rate although a common trend was observed.

The demand-side management includes several techniques for reshaping the pattern and magnitude of end-use electricity consumption. The load shifting, which represents the reallocation of the load demand from periods with high energy deficit toward periods with surplus PV production, is the most common and well-studied DSM strategy [15]. The adoption of this DSM technique in households is of remarkable importance as PV systems are often applied at this scale and the increasing electrification of heating and cooling loads in households provides greater flexibility [16]. However, as highlighted by Widén [17], the DSM capacity to increase self-sufficiency is currently limited given the low consumer engagement, the existence of a large number of low power loads, and the difficulties associated with the automation of such loads. The combination of DSM with battery storage is an interesting solution for optimizing the PV energy utilization and for further increasing the self-consumption. Castillo-Cagigal et al. [18,19] analysed the benefits of the inclusion of energy storage and DSM in a household equipped with a $5.5 \mathrm{~kW}_{\mathrm{p}}$ grid-connected PV system. The authors proved the benefits in terms of increased self-consumption, decreased energy losses, reduction of storage size, and 
increased possibilities for electricity management. Femia et al. [20] investigated the self-consumption rate of PV residential applications equipped with energy storage and using a load management strategy, demonstrating that a synergic use of the load-shifting minimizes the energy exchanged with the grid. In [21], the authors confirmed that the improvements in self-consumption from load shifting and battery storage are roughly additive, especially for small battery capacities.

Most of the cited studies evaluate the achievable self-consumption rate by assuming actual values for energy consumption and PV production. However, to achieve optimal battery management and effective load shifting, the PV generation curve should be determined in advance. The use of solar radiation forecasting to optimize the energy self-consumption rate in houses equipped with PV-storage and energy management systems is one of the most relevant aspects that needs further investigation [10]. Numerous solar radiation forecasting models currently exist, including Numerical Weather Prediction (NWP) models, statistical models, and hybrid combinations [22]. Moreover, several studies in literature deal with the effects of weather forecast uncertainty on the energy management system of the building. Marinelli et al. [23] proposed a control strategy for the energy management of a grid-connected PV plant, where the weather forecast is used for the scheduled hourly production while a storage system is used for compensating the deviation from the forecasted energy plan. Petersen et al. [24] investigated the effect of weather forecast uncertainty on the energy use and indoor climate of a building by adopting a deterministic predictive control system. Wang et al. [25] proposed an energymanagement strategy for a hybrid renewable energy system where the weather forecast uncertainty is minimized by adopting a receding horizon optimization strategy. Masa-Bote et al. [26] analysed the effect of the forecast uncertainty associated with a residential PV system equipped with a $6 \mathrm{kWh}$ battery bank. The results demonstrated that the differences in the annual self-consumption rate between the forecast model and the reference ideal predictor model are small.

The analysis of the literature demonstrates that the involvement of weather forecast data for the optimal allocation of deferrable loads and the optimal management of the battery bank is a fundamental task for the improvement of the self-consumption rate. However, the influence of the weather forecast uncertainty on the actual performance of PV home systems equipped with a battery bank and characterized by a certain share of deferrable loads is not thoroughly analysed. Moreover, the investigation of the most suitable optimization approach, deterministic or stochastic, for the prediction of the PV daily power production starting from the weather forecast data and the maximization of the self-consumption rate is a further open issue.

For this reason, the aim of this paper is to investigate the effect of the weather forecast uncertainty on the achievable self-consumption rate of residential applications equipped with a PV-battery system and characterized by a certain share of deferrable loads. The weather forecast data delivered by two weather forecast services throughout one year are used as input data for the determination of optimal allocation of deferrable loads and optimal dispatch of the battery system. The real weather conditions are subsequently used for determining the actual energy flows and the achieved self-consumption rate. Two different optimization approaches are considered for dealing with uncertainty in weather forecast. In the first approach, called 
deterministic, the expected PV production is evaluated according to the forecast data without considering any uncertainty. In the second approach, a stochastic model is developed and different scenarios based on measured error in the Global Horizontal Irradiance (GHI) are involved in the determination of the optimum. The results obtained are then compared with the theoretical potential (i.e. perfect weather forecast). The achieved selfconsumption rate is determined for different values of PV size, battery capacity, and percentages of deferrable loads. In order to provide statistically significant self-consumption indicators, 150 different user profiles are considered. Finally, a preliminary economic analysis is carried out and the economic profitability of increasing the self-consumption by increasing both the battery capacity and the share of deferrable loads is investigated.

\section{Load profiles and meteorological data}

For the determination of household prosumers' self-consumption, two fundamental yearly data sources are required: the meteorological data for the determination of the PV power production and the electricity load demand. Both of these types of data vary with the location considered, users' habits, and other specific circumstances. For this reason, in order to obtain reliable self-consumption indexes, 150 different user profiles are computed by referring to the database proposed by Quoilin et al. [13]. This database was built up from several data sources of historical household electrical consumption profiles monitored in a project funded by the European Union, called REMODECE (Residential Monitoring to Decrease Energy Use and Carbon Emissions in Europe [27]). The collected data were used for the calibration of a stochastic noise model, and 894 synthetic profiles, which properly represent the variability of household consumption patterns, were generated. Only the 150 Italian load profiles are considered in this study and Figure 1 shows their main characteristics. In particular, Figure 1(a) shows the average daily electrical consumptions in ascending order together with the corresponding confidence intervals. The latter is representative of the daily consumptions variations throughout the year respect to the average value, which depends season, user habits etc. (as shown in the figure, user profiles with a similar average load consumption can be characterized by very different confidence intervals). The average load consumption by referring to the considered 150 load profiles is 3.3 $\mathrm{MWh} /$ year with a standard deviation of $1.32 \mathrm{MWh} /$ year. In addition to the daily load consumption, the considered user profiles differ for the shape of the daily load curve. Figure 1(b) shows the annual average daily load curve represented in relative terms (calculated as the ratio between the hourly load demand and the corresponding daily load request). As expected, the lowest load demand is observed during the night while the peak load occurs during the evening. However, the actual relative hourly demand differs from the average one in function of the considered load profile and, as demonstrated by the confidence intervals, a large dispersion from the mean load value may occur depending on the user profile.

As the case study, the weather conditions measured in Rome (Italy) in the period from 1 September 2015 to 31 August 2016 are considered for the evaluation of the actual PV production. The weather data set includes solar radiation (both global horizontal irradiance and direct normal irradiance), ambient temperature, wind speed, and direction. Actually, the weather conditions are available for 340 days (equal to $93 \%$ of the annual meteorological conditions) due to problems that occurred in the weather station. On the other hand, the missing days were distributed throughout the year and therefore, it is assumed that they do not influence the yearly 
performance. Figure 2 shows the daily GHI and the mean ambient temperature measured during the period under consideration.
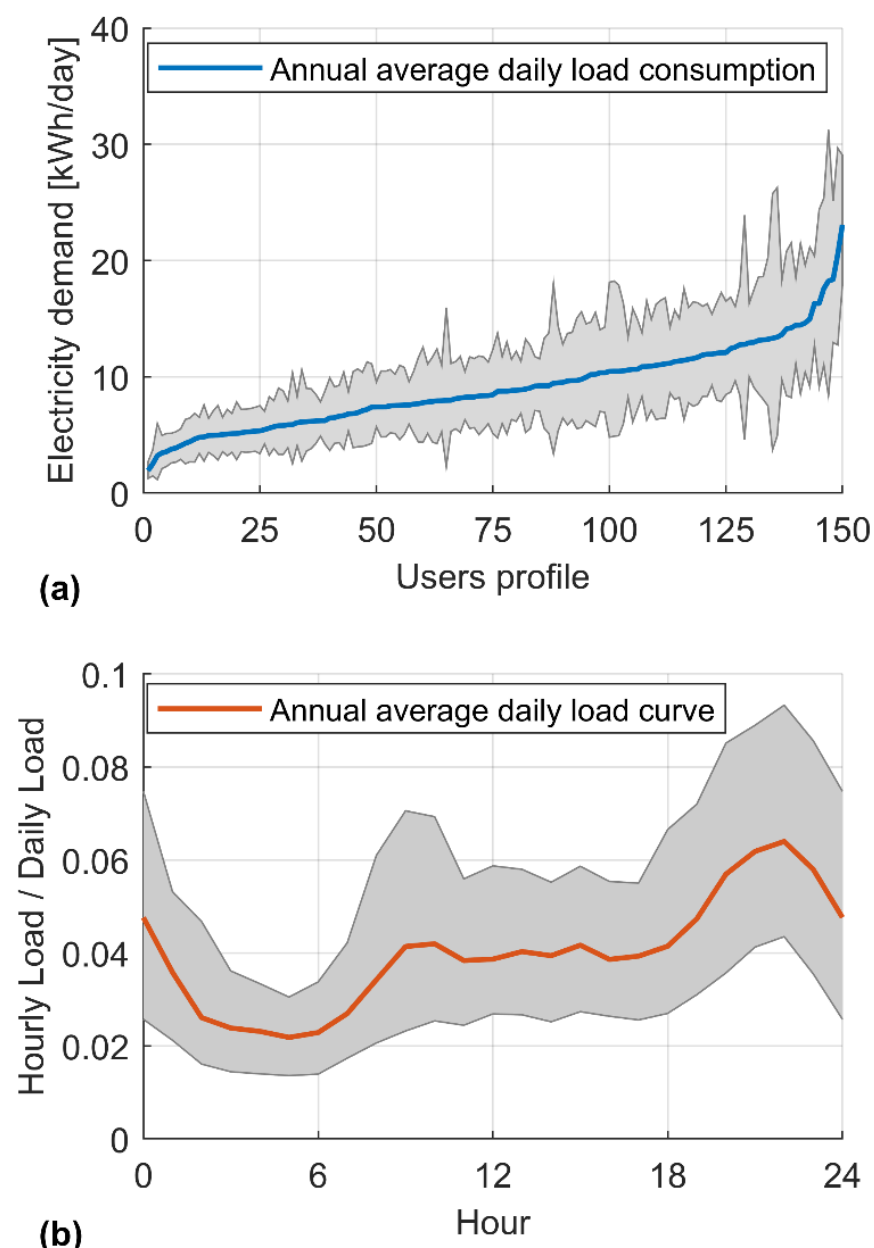

Figure 1 - (a) Annual average daily load consumption and (b) annual average daily load curve for the considered 150 user profiles.

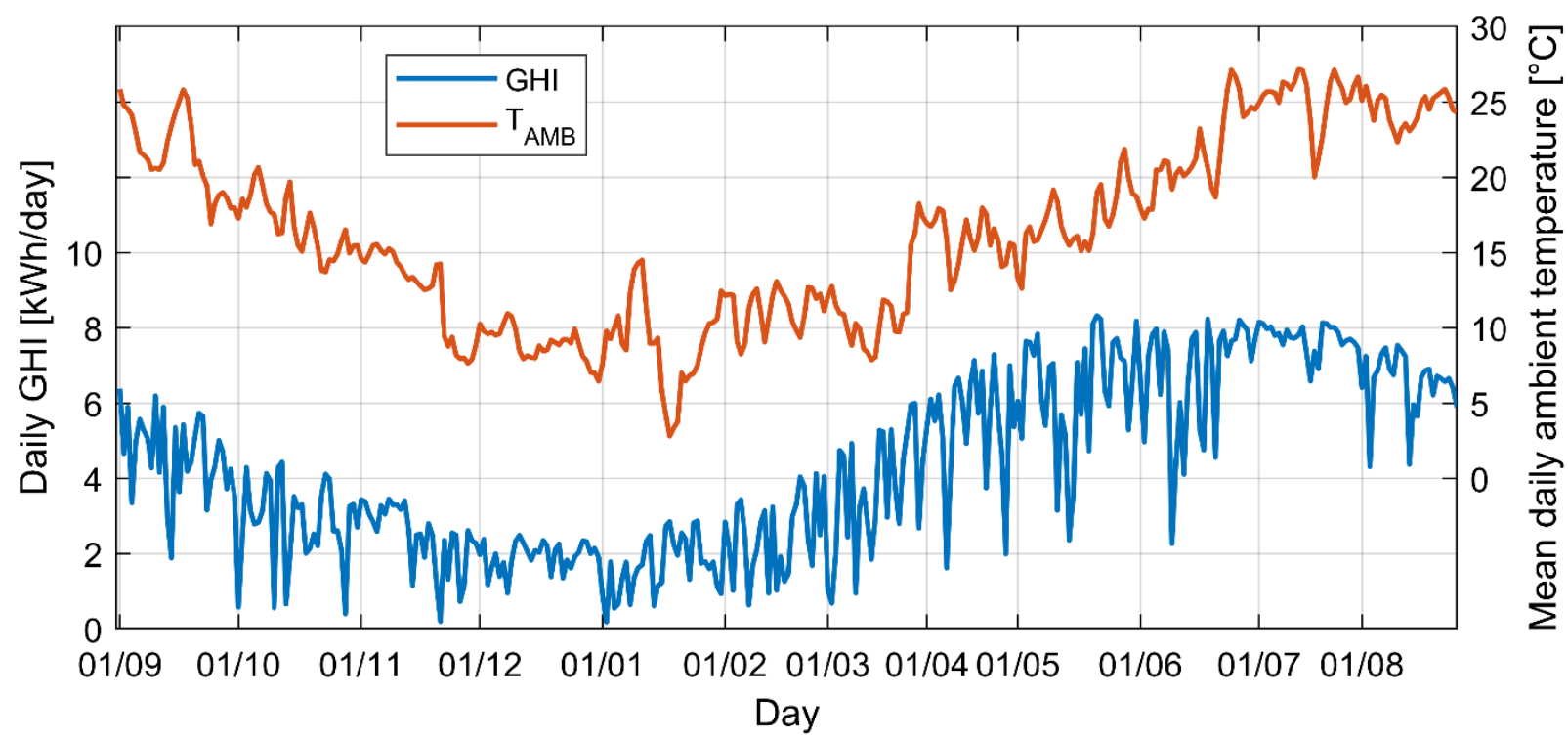

Figure 2 - Daily GHI and mean ambient temperature measured in Rome in the period from 1 September 2015 to 31 August 2016 


\subsection{Weather forecast accuracy}

In this study, two different weather forecast services are considered. The first weather forecast service (called WFS-1) is a commercial product [28] that provides the forecast for the main meteorological parameters such as solar radiation (direct, diffuse, and global), ambient temperature, relative humidity, wind direction, and speed. The forecast is given with a time horizon of 72 hours and a planned update for each hour. The service is based on a combination of various forecasting models. In particular, a mix between the global forecast system model, the European centre for medium-range weather forecasts model, and the high resolution limited area model is used for the long-term forecast. The forecast is then corrected and updated every hour through an appropriate model output statistics algorithm that takes into account the latest data measured by weather stations near to the point of interest. Indeed, the second weather forecast service (WFS-2) is an innovative service developed by ENEA (Italian National Agency for New Technologies, Energy and Sustainable Economic Development) [29]. This service provides the solar radiation forecast (normal direct, global, and diffuse on the horizontal plane) with hourly time resolution and daily updates. It is based on the estimates of cloud cover issued on the Internet by different weather forecast services, which are subsequently used in a developed regressive model.

In this section, the results obtained in terms of accuracy for the two weather forecast services are given and discussed. This analysis is carried out by comparing the data provided by the two weather forecast services with the data measured in Rome during the period under investigation. Therefore, the errors may be caused both either by the inaccuracy of the forecast algorithm and the original data used by the service to determine the weather prediction. The metrics for evaluating the accuracy of the solar energy forecasting refer to those proposed by Zhang et al. [30]. Both of the forecast services are set with a forecast horizon of $72 \mathrm{~h}$ and a resolution of $1 \mathrm{~h}$. The uncertainty occurring over the analysed period in terms of daily GHI for the two services is reported in Table 1. The root mean square error (RMSE), mean absolute error (MAE), and mean bias error (MBE) are used as metrics for the three-day forecast horizon.

Table 1 - GHI forecast accuracy metrics for the two forecast services.

\begin{tabular}{|c|ccc|ccc|}
\hline & \multicolumn{3}{|c|}{ WFS-1 } & \multicolumn{3}{c|}{ WFS-2 } \\
& $R M S E$ & $M A E$ & $M B E$ & $R M S E$ & $M A E$ & $M B E$ \\
& {$\left[\mathrm{kWh} / \mathrm{m}^{2}\right]$} & {$\left[\mathrm{kWh} / \mathrm{m}^{2}\right]$} & {$\left[\mathrm{kWh} / \mathrm{m}^{2}\right]$} & {$\left[\mathrm{kWh} / \mathrm{m}^{2}\right]$} & {$\left[\mathrm{kWh} / \mathrm{m}^{2}\right]$} & {$\left[\mathrm{kWh} / \mathrm{m}^{2}\right]$} \\
\hline First day (1-24 h) & 0.622 & 0.469 & -0.035 & 1.137 & 0.812 & 0.256 \\
Second day (25-48 h) & 1.206 & 0.887 & 0.035 & 1.545 & 1.141 & 0.255 \\
Third day (49-72 h) & 1.377 & 1.052 & -0.042 & 1.684 & 1.240 & 0.250 \\
\hline
\end{tabular}

As expected, the GHI prediction becomes less accurate with the increase of the forecast horizon. The RMSE observed for the first day ahead is about $15 \%$ of the mean daily irradiance occurring during the year for WFS1 and 26\% for WFS-2. Referring to the MBE, which identifies the long-term trend of the forecast method, the WFS-1 is characterized by a small negative value; that is, this service slightly underestimates the solar radiation. Conversely, the WFS-2 shows a positive MBE with an overestimation of the solar radiation. The 
WFS-1 achieves a higher accuracy than the WFS-2 in the period under evaluation as lower RMSE and MAE values occur. Besides the analysis of the accuracy of the daily available solar radiation, investigation of the accuracy of the hourly GHI forecast is fundamental. In fact, the maximization of self-consumption requires information about both the amount and the shape of available PV power production. The latter is fundamental especially for the efficient deployment of demand-side management techniques. Figure 3 shows the probability distribution function of the uncertainty of the hourly GHI. The latter refers to the short-term forecast of GHI values delivered during sunlight hours for the following hour. Figure 3 also shows the best fit of a normal distribution (dashed line) with the measured data. With the use of WFS-1 data (Figure 3(a)), the hourly GHI error is characterized by a rather symmetrical distribution with respect to the zero. The occurrence of GHI errors in the range of $\pm 100 \mathrm{~W} / \mathrm{m}^{2}$ is characterized by high probability values while the occurrence of GHI errors higher than $200 \mathrm{~W} / \mathrm{m}^{2}$ is very infrequent. The goodness of the fit with a normal distribution is confirmed by a coefficient of determination (R-square) equal to $92.7 \%$. The overestimation of the GHI prediction by using the WFS-2 is confirmed by Figure 3(b), where the mean hourly GHI error is about $20 \mathrm{~W} / \mathrm{m}^{2}$. The fitting of a normal distribution is characterized by a lower R-square (83.8\%) compared with the WFS-1 case.
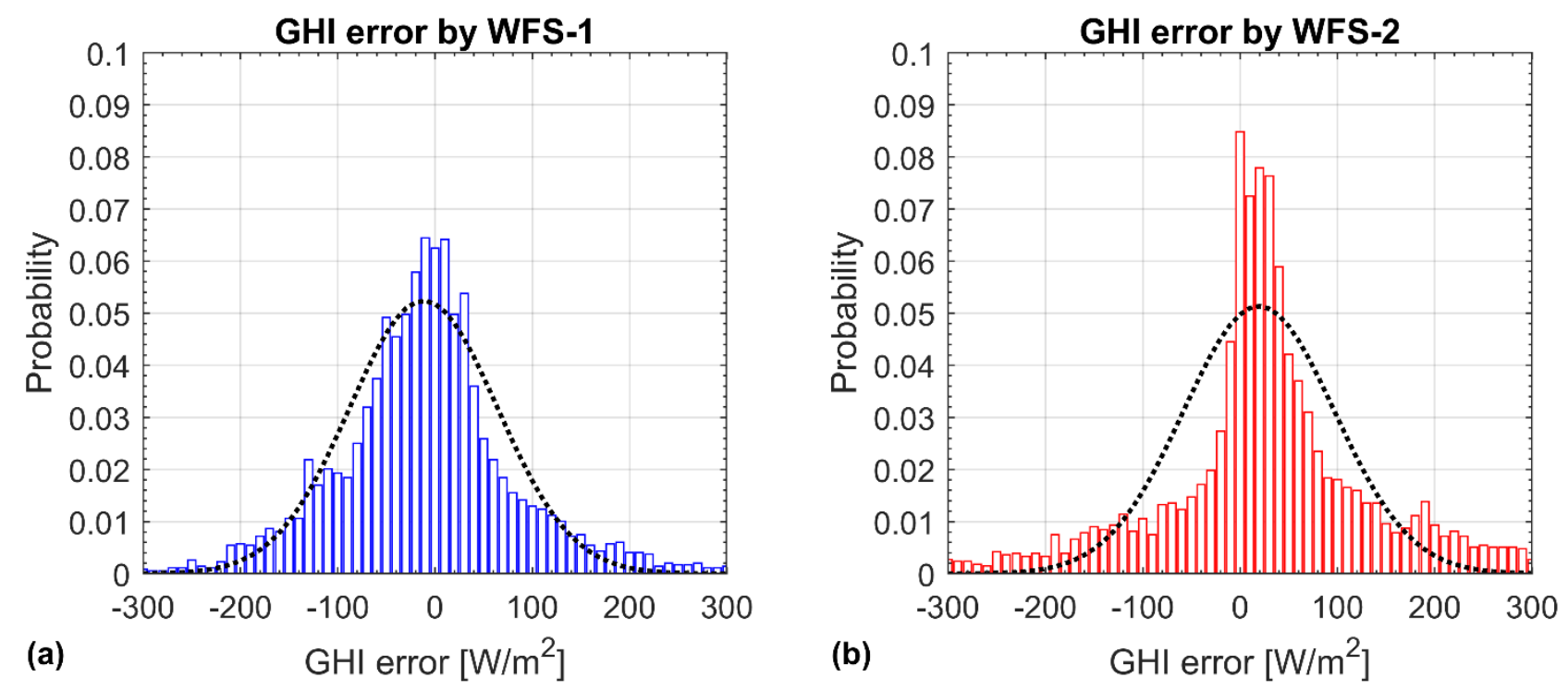

Figure 3 - Probability distribution function of the uncertainty in the hourly GHI for the two weather forecast services under consideration.

\section{Model description}

Specific simulation models implemented in Matlab are used to evaluate the expected performance of both the PV system and the battery bank as a function of their main design parameters. An optimization approach based on a linear programming problem is developed to find the best allocation of deferrable loads and the optimal dispatch of the battery bank. The specific optimization algorithm is implemented under GAMS environment using CPLEX solver and a proper interface between the two software is adopted. 


\subsection{PV system}

The PV generation profile is simulated by using the meteorological data presented in the previous section and the performance parameters of a modular PV section. The latter is based on a $250 \mathrm{~W}_{\mathrm{p}} \mathrm{PV}$ module while the number of PV panels and, consequently, the overall PV size, is evaluated according to the annual energy production of a single module and the considered load profile.

The main PV module characteristics are reported in Table 2. Although PV orientation varies with the household characteristics, such as roof orientation, shading, and latitude, for the sake of simplicity, it is assumed that in every case the modules are oriented towards the south (azimuth equal to $0^{\circ}$ ) with a tilt angle of $30^{\circ}$. Therefore, the Global Irradiation GI available on the surface of the PV modules is calculated from the GHI through the method proposed by Duffie and Beckman [31]. The effect of cell temperature $\left(\mathrm{T}^{\mathrm{PV}}\right.$ ) on PV performance is also involved in the model, according to the equations proposed in [31].

In particular, the actual PV efficiency $\eta_{\mathrm{t}}^{\mathrm{PV}}$ at time $\mathrm{t}$ depends on the nominal PV efficiency $\eta^{\mathrm{PV} \text {,NOM }}$ according to the following relationship:

$$
\eta_{\mathrm{t}}^{\mathrm{PV}}=\eta^{\mathrm{PV}, \mathrm{NOM}}\left[1-\gamma\left(\mathrm{T}_{\mathrm{t}}^{\mathrm{PV}}-\mathrm{T}^{\mathrm{STC}}\right)\right]
$$

where $\gamma$ is the temperature coefficient and $\mathrm{T}^{\mathrm{STC}}$ is the PV temperature under standard test conditions (equal to $25^{\circ} \mathrm{C}$ ). Finally, the power output of the PV panel is given by:

$$
\mathrm{P}_{\mathrm{t}}^{\mathrm{PV}, \mathrm{ref}}=\mathrm{GI}_{\mathrm{t}} \cdot \mathrm{A} \cdot \eta_{\mathrm{t}}^{\mathrm{PV}} \cdot \eta_{\mathrm{t}}^{\mathrm{INV}} \cdot \mathrm{f}^{\mathrm{PV}}
$$

where $A$ is the overall active area of the reference PV module, $\eta^{\mathrm{INV}}$ is the inverter efficiency (it is assumed that the inverter is connected to a sub-array composed by four PV modules), which is given by the manufacturer as a function of the $\mathrm{PV}$ power output [32], and $\mathrm{f}^{\mathrm{PV}}$ is the derating factor. The latter takes into account soiling of modules, wiring losses, shading, snow cover, aging, and other secondary losses.

Table 2 - Main parameters of the PV system [31-34].

\begin{tabular}{lclc}
\hline Solar cell technology & Polycrystalline & Derating factor f & 0.84 \\
Nominal PV power P & & & \\
& $250 \mathrm{~W}, \mathrm{NOM}$ & Inverter nominal efficiency & $97.8 \%$ \\
Nominal PV efficiency $\eta^{\mathrm{PV}, \mathrm{NOM}}$ & $14.9 \%$ & Active area (A) & $1.675 \mathrm{~m}^{2}$ \\
Nominal Operating Cell Temperature & $46^{\circ} \mathrm{C}$ & Temperature coeff. of power $(\gamma)$ & $0.41 \% / \mathrm{K}$ \\
& & & \\
\hline
\end{tabular}

Starting from the expected performance of the single PV panel, the annual energy production of the PV plant $\left(\mathrm{E}^{\mathrm{PV}, \mathrm{ref}}\right)$ is calculated according to the given meteorological conditions. Due to differences in annual energy consumption, each household is characterized by a different PV size. However, a constant PV-to-load ratio 
$\left(\mathrm{R}_{\mathrm{PV}}\right)$ has been assumed for all households. The PV-to-load ratio (or relative PV size) is defined as the ratio between the annual PV production and the annual energy consumption of the household:

$$
\mathrm{R}_{\mathrm{PV}_{\mathrm{l}}}=\frac{\mathrm{E}_{\mathrm{l}}^{\mathrm{PV}}}{\mathrm{E}_{\mathrm{l}}^{\mathrm{TL}}}=\frac{\mathrm{E}^{\mathrm{PV}, \mathrm{ref}} \cdot \mathrm{n}_{\mathrm{l}}^{\mathrm{PV}}}{\mathrm{E}_{\mathrm{l}}^{\mathrm{TL}}}
$$

where $\mathrm{E}_{l}^{\mathrm{TL}}$ is the annual load consumption of the household $\mathrm{l}$ and $\mathrm{n}_{\mathrm{l}}^{\mathrm{PV}}$ is the number of installed PV modules in the considered household. As mentioned, the assumption of a constant ratio between annual energy production and annual energy consumption results in a different size of PV system but allows the same potential self-sufficiency for each household profile.

\subsection{Battery storage system}

The use of batteries as electrical energy storage is the most common solution for increasing the selfconsumption of prosumers, improving the reliability of the power supply and maintaining a high power quality level. The high variability of solar radiation during the day causes fast and poorly predictable fluctuation of PV production and the presence of a battery bank is fundamental to smooth the PV power output curve. Moreover, battery storage allows the achievement of time-shifting of PV production in order to maximize the self-consumption of the household. In this study, the available energy content of the battery bank is evaluated through the so-called "state of charge" (SOC.). The latter is the ratio between the stored energy and the nominal storage capacity and is calculated by monitoring the charging $\left(\mathrm{P}^{\mathrm{BC}}\right)$ and discharging power $\left(\mathrm{P}^{\mathrm{BD}}\right)$ over time:

$$
\operatorname{SOC}_{t}=\operatorname{SOC}_{t-1}+\frac{\left(\mathrm{P}_{t}^{\mathrm{BC}} \cdot \eta^{\mathrm{BC}}-\mathrm{P}_{\mathrm{t}}^{\mathrm{BD}} / \eta^{\mathrm{BD}}\right) \Delta \mathrm{t}}{\mathrm{E}^{\mathrm{B}}}
$$

where $\eta^{B C}$ and $\eta^{B D}$ are the battery efficiencies during the charge and discharge processes respectively, $\Delta t$ is the applied time step, and $\mathrm{E}^{\mathrm{B}}$ is the battery nominal capacity. The battery efficiency depends on several operating parameters such as current, SOC and battery lifetime. To simplify the model, this study considers lithium-ion batteries characterized by a constant round-trip efficiency of $90 \%$ while the SOC ranges from $10 \%$ to $90 \%$ [35].

The rated storage capacity is determined as a function of the annual electricity demand. In particular, similarly to the PV array, a battery capacity ratio $R_{B}$ has been assumed constant independently from the load profile. The battery capacity ratio is given by the ratio of battery capacity to household annual consumption, has been considered:

$$
\mathrm{R}_{\mathrm{B}_{1}}=\frac{\mathrm{E}^{\mathrm{B}}}{\mathrm{E}_{\mathrm{l}}^{\mathrm{TL}}}\left[\frac{\mathrm{kWh}}{\mathrm{MWh}}\right]
$$

Consequently, a different battery nominal capacity is calculated for each household profile, as a function of the annual load consumption. 


\subsection{Load demand}

As mentioned, 150 different household profiles are considered in this study. However, with the aim of investigating the benefits arising from the implementation of a suitable demand-side management strategy in the prosumer self-consumption, two types of electrical demand are considered:

a. Deferrable loads, defined as the load demands that can be displaced along the day. Electrical appliances such as washing machines, dryers, and dishwashers are included in this category. The amount of energy required by deferrable loads must be delivered during the day, but no constraints are introduced in the load profiles.

b. Non-deferrable loads, defined as the energy demand that is not controllable. They represent the instantaneous consumption of lights, TVs, and so on and the continuous consumption of fridges, computers, and so on. In this case, both the daily energy consumption and the shape of the load curve are fixed.

The amount of deferrable loads is determined here by considering a Deferrable Load Ratio (DLR), which is defined as the ratio of the daily deferrable load demand $\mathrm{E}^{\mathrm{DL}}$ and the overall daily load demand:

$$
\operatorname{DLR}_{1}=\frac{E_{l}^{D L}}{E_{l}^{T L}}=\frac{E_{l}^{D L}}{E_{l}^{D L}+E_{l}^{N D L}}
$$

where $\mathrm{E}^{\mathrm{NDL}}$ is the amount of the daily non-deferrable load demand. For the sake of simplicity, in this analysis it is assumed that DLR is constant throughout the year and the overall daily load demand is perfectly known, although the non-deferrable load demand are usually unpredictable.

\subsection{Optimization problem}

The evaluation of the PV electricity self-consumption and the self-sufficiency of the household prosumer requires, in addition to the PV-battery system simulation, the resolution of an optimization problem for the optimal allocation of deferrable loads and the optimal dispatch of the battery system. In fact, the objective of maximizing the household self-consumption and self-sufficiency is reached by minimizing the amount of electricity purchased from the grid and by maximizing the exploitation of the PV electrical generation in order to avoid electricity sales to the grid. The presence of deferrable loads (i.e. washing machines, dishwashers, etc.) and their share in the overall load demand strongly influences the optimal achievable target in terms of self-consumption of the user. The optimization tool operates the displacement of deferrable loads, reshaping the load curve in order to find the best fit between the PV power generation and the load demand. In particular, the supply of deferrable load demand is generally delivered during periods characterized by high levels of PV electrical generation.

Even the battery management is involved in the optimization problem through a suitable dispatch of the charging and discharging of the battery system. Obviously, the benefits arising from the introduction of a battery system in the self-consumption of the household user increase with the storage capacity. The solution 
of the optimization problem defines the amount of both excess energy to be stored and energy deficit to be covered by the batteries. The optimization model is set with a time-step of 1 hour and is formulated as a mixedinteger linear programming (MILP). In particular, the continuous variables refer to energy flows, while binary variables indicate the involvement or not $(1 \mid 0)$ of the different devices. The mathematical problem is formulated in the following form:

$$
\begin{aligned}
& \max \sum_{l \in \mathrm{L}} \sum_{\mathrm{t} \in \mathrm{T}} \mathrm{P}_{\mathrm{t}, \mathrm{l}}^{\mathrm{DIR}} \cdot \Delta \mathrm{t} \\
& \mathrm{P}_{\mathrm{t}, \mathrm{l}}^{\mathrm{DIR}}=\operatorname{Min}\left\{\mathrm{P}_{\mathrm{t}, \mathrm{l}}^{\mathrm{DL}}+\mathrm{P}_{\mathrm{t}, \mathrm{l}}^{\mathrm{NDL}} ; \mathrm{P}_{\mathrm{t}, \mathrm{l}}^{\mathrm{PV}}-\mathrm{P}_{\mathrm{t}, \mathrm{l}}^{\mathrm{BC}}+\mathrm{P}_{\mathrm{t}, \mathrm{l}}^{\mathrm{BD}}\right\} \\
& \mathrm{P}_{\mathrm{t}, \mathrm{l}}^{\mathrm{PV}}+\mathrm{P}_{\mathrm{t}, \mathrm{l}}^{\mathrm{BD}}+\mathrm{P}_{\mathrm{t}, \mathrm{l}}^{\mathrm{PUR}}=\mathrm{P}_{\mathrm{t}, \mathrm{l}}^{\mathrm{DL}}+\mathrm{P}_{\mathrm{t}, \mathrm{l}}^{\mathrm{NDL}}+\mathrm{P}_{\mathrm{t}, \mathrm{l}}^{\mathrm{BC}}+\mathrm{P}_{\mathrm{t}, \mathrm{l}}^{\mathrm{SEL}} \\
& \quad \sum_{\mathrm{t}=(\mathrm{k}-1) \cdot 24+1}^{\mathrm{k} \cdot 24} \mathrm{P}_{\mathrm{t}, \mathrm{l}}^{\mathrm{DL}} \cdot \Delta \mathrm{t}=\mathrm{E}_{\mathrm{l}}^{\mathrm{DL}} \forall \mathrm{k}=1, \ldots 365 \\
& \mathrm{P}_{\mathrm{t}, \mathrm{l}}^{\mathrm{BD}}, \mathrm{P}_{\mathrm{t}, \mathrm{l}}^{\mathrm{BC}} \leq \mathrm{P}^{\mathrm{B}, \mathrm{MAX}} \\
& \operatorname{SOC}^{\mathrm{MIN}} \leq \mathrm{SOC}_{\mathrm{t}, \mathrm{l}} \leq \mathrm{SOC}^{\mathrm{MAX}} \\
& \mathrm{P}_{\mathrm{t}, \mathrm{l}}^{\mathrm{PUR}}, \mathrm{P}_{\mathrm{t}, \mathrm{l}}^{\mathrm{BD}}, \mathrm{P}_{\mathrm{t}, \mathrm{l}}^{\mathrm{BC}}, \mathrm{P}_{\mathrm{t}, \mathrm{l}}^{\mathrm{SEL}}, \mathrm{P}_{\mathrm{t}, \mathrm{l}}^{\mathrm{D}} \geq 0
\end{aligned}
$$

The objective function (7) is based on the maximization of the sum of the hourly electricity $\mathrm{P}_{\mathrm{t}, \mathrm{l}}^{\mathrm{DIR}} \cdot \Delta \mathrm{t}$ selfconsumed relative to time $\mathrm{t}$ by the household $\mathrm{l}$ (where $\mathrm{T}$ is the set of all time steps and $\mathrm{L}$ is the set of all considered household profiles). In (8), the power generated by the PV system that directly feeds the load ( $\mathrm{P}_{\mathrm{t}, 1}^{\mathrm{DIR}}$ ) is defined as the minimum between the overall load demand $\left(\mathrm{P}_{\mathrm{t}, \mathrm{l}}^{\mathrm{DL}}+\mathrm{P}_{\mathrm{t}, \mathrm{l}}^{\mathrm{NDL}}\right)$ and the $\mathrm{PV}+$ battery power delivery. In (9), the equality constraint of the household power balance is imposed for each time step and each household profile. The main power input is the electrical power produced by the $\mathrm{PV}$ system $\mathrm{P}_{\mathrm{t}, \mathrm{l}}^{\mathrm{PV}}$, which is equal to the reference PV production $\mathrm{P}_{t}^{\mathrm{PV} \text {,ref }}$ multiplied by the number of sub-modules $\mathrm{n}_{\mathrm{l}}^{\mathrm{PV}}$; the electricity purchase from the grid $\left(\mathrm{P}_{\mathrm{t}, \mathrm{l}}^{\mathrm{PUR}}\right)$ or the electricity from the battery system $\left(\mathrm{P}_{\mathrm{t}, \mathrm{l}}^{\mathrm{BD}}\right)$ is used to suitably meet the load demand. The main power output is the household electricity demand subdivided into deferrable $\left(\mathrm{P}_{\mathrm{t}, \mathrm{l}}^{\mathrm{DL}}\right)$ and non-deferrable $\left(\mathrm{P}_{\mathrm{t}, \mathrm{l}}^{\mathrm{NDL}}\right)$ loads. The excess power production could be sold to the grid $\left(\mathrm{P}_{\mathrm{t}, \mathrm{l}}^{\mathrm{SEL}}\right)$ or stored in the battery system $\left(\mathrm{P}_{\mathrm{t}, \mathrm{l}}^{\mathrm{BC}}\right)$. It is worth noting that $\mathrm{P}_{\mathrm{t}, \mathrm{l}}^{\mathrm{PV}}$ and $\mathrm{P}_{\mathrm{t}, \mathrm{l}}^{\mathrm{NDL}}$ are not variables but inputs of the optimization problem. On the other hand, the deferrable load profile is involved in the optimization process, since only the daily energy consumption but not the shape of the load curve is defined. For this reason, in (10), the constraint of meeting the daily amount of deferrable load demand $\left(\mathrm{E}_{\mathrm{l}}^{\mathrm{DL}}\right)$ is introduced. In (11), a maximum battery charging and discharging power $\left(\mathrm{P}^{\mathrm{B}, \mathrm{MAX}}\right)$ is introduced since efficiency decreases considerably for high power flows. In (12), the battery state of charge is constrained to range between a minimum (SOC ${ }^{\mathrm{MIN}}$ ) and a maximum value $\left(\mathrm{SOC}^{\mathrm{MAX}}\right)$. Finally, in (13), all the continuous variables are constrained to assume only positive values.

The energy flows calculated through the optimization problem are used for the determination of the selfconsumption and self-sufficiency of the households. These two parameters are the main output of this analysis and are defined according to Luthander et al. [6]. The self-consumption rate (SCR) is defined as the electricity 
generated in house and consumed locally by the household $\left(\mathrm{E}^{\mathrm{DIR}}=\sum_{\mathrm{t} \in \mathrm{T}} \mathrm{P}_{\mathrm{t}, \mathrm{l}}^{\mathrm{DIR}} \cdot \Delta \mathrm{t}\right)$ divided by the overall PV generation $\left(\mathrm{E}^{\mathrm{PV}}\right)$ :

$$
\mathrm{SCR}_{\mathrm{l}}=\frac{\mathrm{E}_{\mathrm{l}}^{\mathrm{DIR}}}{\mathrm{E}_{\mathrm{l}}^{\mathrm{PV}}}
$$

Similarly, the self-sufficiency rate (SSR) is defined as the ratio between the self-consumed energy $\mathrm{E}^{\mathrm{DIR}}$ and the annual energy consumption of the household:

$$
\mathrm{SSR}_{\mathrm{l}}=\frac{\mathrm{E}_{\mathrm{l}}^{\mathrm{DIR}}}{\mathrm{E}_{\mathrm{l}}^{\mathrm{TL}}}
$$

It is worth noting that, by imposing a PV-to-load ratio $\mathrm{R}_{\mathrm{PV}}=1$, the annual self-consumption rate and selfsufficiency rate coincide.

\subsection{Case studies}

Three different cases are considered in this analysis. Firstly, an ideal case is evaluated, where both the load profile and the PV electricity generation are perfectly known. Secondly, the influence of uncertainty in the weather forecast on the achieved self-consumption values when adopting a deterministic approach is investigated. Finally, the possible benefits attained by using a stochastic approach instead of a deterministic one are assessed.

\subsubsection{Ideal case}

The real weather conditions are introduced as input data in the simulation model of the PV. The optimization problem is therefore set as a deterministic problem with a time horizon of one year, where both the real nondeferrable load profile and the PV generation curves are perfectly known. For this reason, the obtained ideal SCR represents the target for the home solar system. In fact, the spread between the obtained ideal SCR and a $100 \%$ self-consumption rate is only due to the use of a non-dispatchable source as solar energy and a limited storage capacity.

\subsubsection{Real case: Deterministic approach}

The use of the weather forecast information to assess the performance of the solar system in terms of selfconsumption is investigated in this case study. The inaccuracy of the solar radiation prediction affects the expected PV power profile and consequently affects the allocation of deferrable loads throughout the day. However, in this section, the possible deviation of the expected PV production with respect to the real one is not considered in the resolution of the optimization problem. In other words, a deterministic approach is adopted as the optimization problem is solved by using the mathematical problem reported in Section 3.4, while the hourly electricity produced by the PV system $\mathrm{P}_{\mathrm{t}, \mathrm{l}}^{\mathrm{PV}}$ is calculated by referring to the meteorological data delivered by the two weather forecast services. Since the weather forecast accuracy decreases with the increase of the forecast time horizon, the yearly optimal solution is composed of daily optimizations with a time horizon of $72 \mathrm{~h}$. The solution found determines the energy management of deferrable loads and battery 
bank, which is then used during the simulation of the actual performance of the PV system. Even in this case study, no uncertainty in both the overall load request and in the profile of the non-deferrable load demand are introduced.

\subsubsection{Real case: Stochastic approach}

As shown in Figure 3, the measured error in the GHI can be fitted with a Gaussian curve and this important information can be introduced in the optimization problem to improve the energy management strategy. Several stochastic programming models are presented in the literature, such as those based on scenario-tree or chance-constrained approaches [36]. However, the choice of the best approach is beyond of the scope of this paper. Therefore, a very simple stochastic model based on the scenarios approach is applied in this study. In particular, starting from the expected PV production profile based on the weather forecast data, two other additional scenarios are considered. The standard deviation is used for generating a pessimistic scenario, in which the expected GHI is decreased by the standard deviation, and an optimistic scenario, in which the expected GHI is increased by the standard deviation. The corresponding percentages of occurrence of the three scenarios are calculated by the probability distribution functions observed in Figure 3. Like the previous approach, the optimization problem is solved for each day considered in this analysis, since the weather forecast have a limited time horizon and the decision in terms of allocation of the deferrable loads and battery management is used during the simulation of the actual home solar system performance.

\section{$4 \quad$ Results and discussion}

The results achieved in terms of self-consumption in the solar house system are presented in this section. Owing to the different load profiles, the achieved results are shown in terms of box plots, where the median value defines the general trend while the box size highlights the dispersion with respect to the median value. As mentioned in the previous section, three main factors are identified for the present analysis: (1) the PV-toload ratio $\left(\mathrm{R}_{\mathrm{PV}}\right)$, which determines the energy generated by the PV system for each household, (2) the relative storage capacity of the batteries $\left(\mathrm{R}_{\mathrm{B}}\right)$, which defines the system capacity of time-shifting the energy production, and (3) the deferrable loads ratio (DLR), which represents the user availability to reshape its demand profile. Compared to the first two factors, which are characterized by potentially unlimited maximum values, the maximum percentage of deferrable load is limited and depends on the share of deferrable loads consumption. In this analysis, a maximum percentage of $40 \%$ is assumed.

Starting from the solar radiation measured in Rome and by implementing the simulation model presented in the section 3.1, the energy production of the single PV module is calculated, resulting equal to about 350 $\mathrm{kWh} /$ year (corresponding to a specific yearly energy production of $1397 \mathrm{kWh} / \mathrm{kW}$ ). This value is assumed constant independently from the PV size, which is different for each household.

\subsection{Ideal case results}

As mentioned, in this first case, the uncertainties in the load profile and weather forecasts are not considered and the results of this ideal case are assumed as the target for the overall study. A first analysis is carried out 
by assuming a $\mathrm{R}_{\mathrm{PV}}=1$, that is, the $\mathrm{PV}$ system is designed to completely supply the annual energy consumption of the specific user $\left(\mathrm{E}^{\mathrm{PV}}=\mathrm{E}^{\mathrm{TL}}\right)$. In this condition, the SCR and the SSR are equivalent. Figure 4 demonstrates that the presence of deferrable loads increases the potential SCR that could be achieved, especially if batteries are not included $\left(\mathrm{R}_{\mathrm{B}}=0\right)$ or for low values of battery capacity.

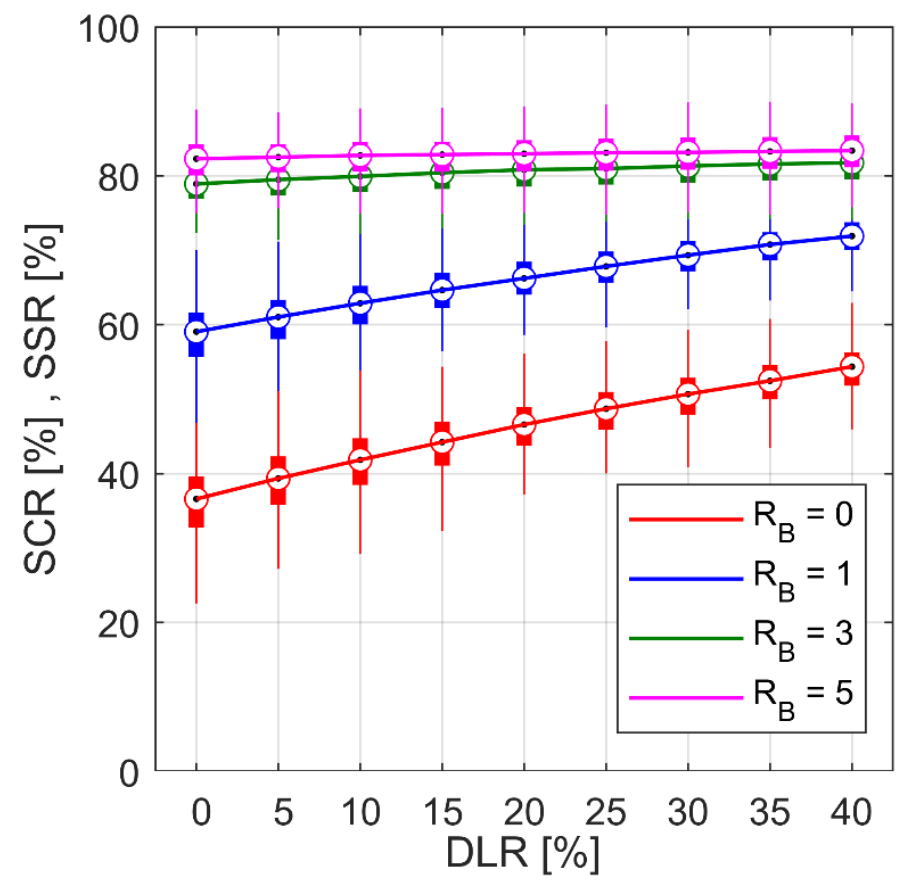

Figure 4 - Self-consumption rate and self-sufficiency rate as a function of deferrable loads ratio for different battery size values (ideal case, $R_{P V}=1$ ).

The benefits of managing a share of consumption becomes more and more marginal with the increase of $\mathrm{R}_{\mathrm{B}}$ due to the large capacity of the storage system to time-shift the excess PV power production. As expected, the SCR shows an asymptotic trend with respect to both DLR and $\mathrm{R}_{\mathrm{B}}$. In fact, a further increase of SCR may require the balancing of weekly or seasonal energy variations, rather than daily ones, and both the battery bank and the DSM technique are unable to perform this task suitably. A reduction of box sizes is also observed with the increase of the storage capacity, highlighting the reduced dependence on the load consumption curve.

Although DLR and $\mathrm{R}_{\mathrm{B}}$ are two independent design factors, the same target SCR value can be achieved with different combinations of these two factors. Figure 5 shows the median SCR as a function of DLR and $\mathrm{R}_{B}$ for $\mathrm{R}_{\mathrm{PV}}=1$. Figure 5 demonstrates that without considering any battery or deferrable load, the SCR of the household is about 37\%. A constant improvement of the SCR occurs by increasing $\mathrm{R}_{\mathrm{B}}$ and DLR to reach a target SCR of about 75\%. A further rise in the SCR should involve a weekly and a seasonal time shift of the PV energy production. In fact, Figure 5 shows that an SCR higher than $80 \%$ is reached only for very high values of DLR and $\mathrm{R}_{\mathrm{B}}$. Moreover, Figure 5 shows that the slope of the iso-SCR lines is almost constant and is equal to about -0.03 . Therefore, for any SCR target value, if the deferrable load ratio increases by one percentage point, the battery capacity ratio decreases by three percentage points. 


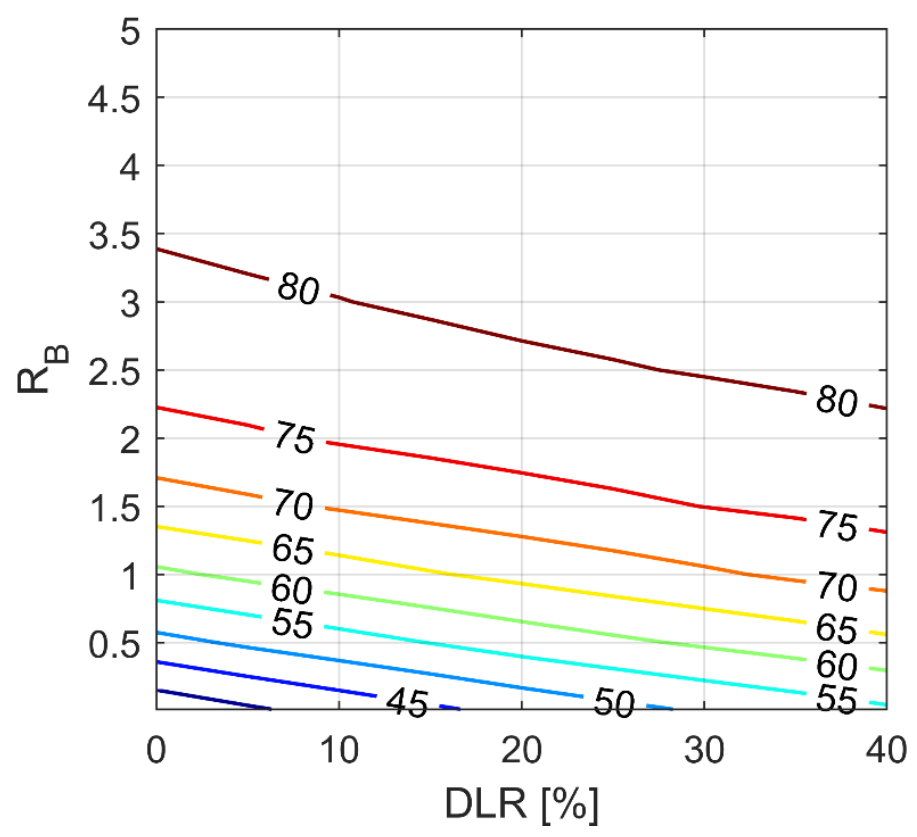

Figure 5 - Influence of deferrable loads ratio and battery size on the median SCR for the ideal case $\left(R_{P V}=\right.$ 1)

Another important design factor of home PV systems is the relative PV size, which causes an opposite effect on the self-consumption rate and on the self-sufficiency rate. In fact, with the increase of $\mathrm{R}_{\mathrm{PV}}$, an excess of electricity production occurs, especially during summer days, but at the same time, a larger share of load consumption is supplied by the on-site PV production during the winter and middle seasons, with a corresponding increase of the system self-sufficiency. Figure 6 shows the median value and box plot of the SSR value as a function of the percentage of deferrable loads and the relative PV size in the case of no battery bank (Figure 6(a)) and with $\mathrm{R}_{\mathrm{B}}=1$ (Figure 6(b)). For low values of $\mathrm{R}_{\mathrm{PV}}$, the benefits arising from a reshaping of the load profile with the introduction of deferrable loads are of minor relevance due to the low frequency of excess energy production periods. In this case, the introduction of a battery bank further reduces the contribution of deferrable loads in the rise of SSR, which becomes negligible. This result is independent from the user profile, as demonstrated by the small size of the box. By increasing $\mathrm{R}_{\mathrm{PV}}$, the dispersion from the median values also increases and the shape of the user profile becomes more and more fundamental for the determination of the target SSR. The flexibility given by the presence of deferrable loads contributes to the increase of the SSR, but even in this case the benefits arising from the increase of $\mathrm{R}_{\mathrm{PV}}$ become more and more marginal in terms of SSR improvement and the introduction of a battery bank is required to achieve SSR values higher than $60 \%$.

Figure 7 shows the self-consumption rate in function of DLR and $R_{P V}$ for the case of $R_{B}=0$ (Figure 7(a)) and $\mathrm{R}_{\mathrm{B}}=1$ (Figure 7(b)). Figure 7 demonstrates that SCR increases as $\mathrm{R}_{\mathrm{PV}}$ decreases. However, this increase in SCR is not due to a rise in the electricity generated in house and consumed there but only due to a decrease of the annual PV production. 

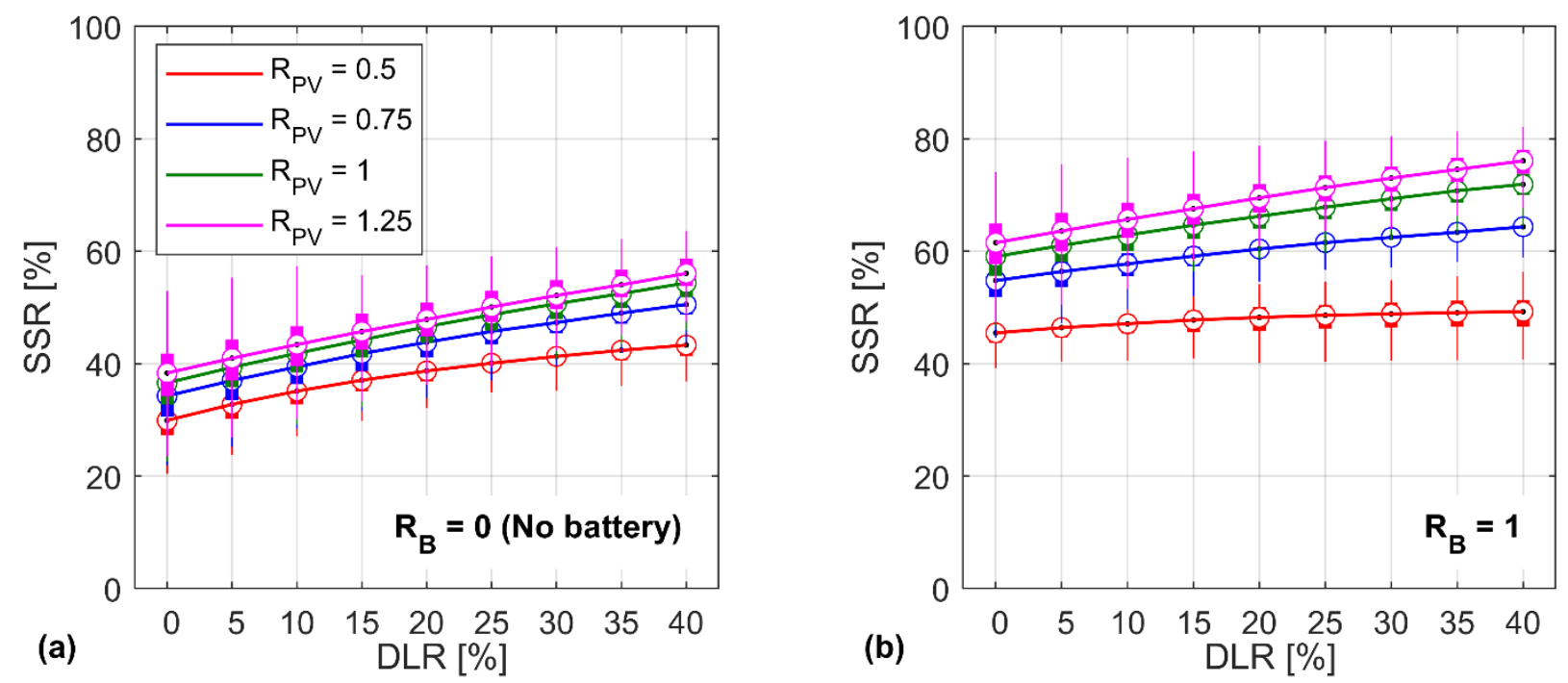

Figure 6 - Box plot of the SSR as a function of deferrable loads ratio for different PV size values (a) without a battery bank (ideal case, $R_{B}=0$ ) and (b) with a battery bank (ideal case, $R_{B}=1$ ).
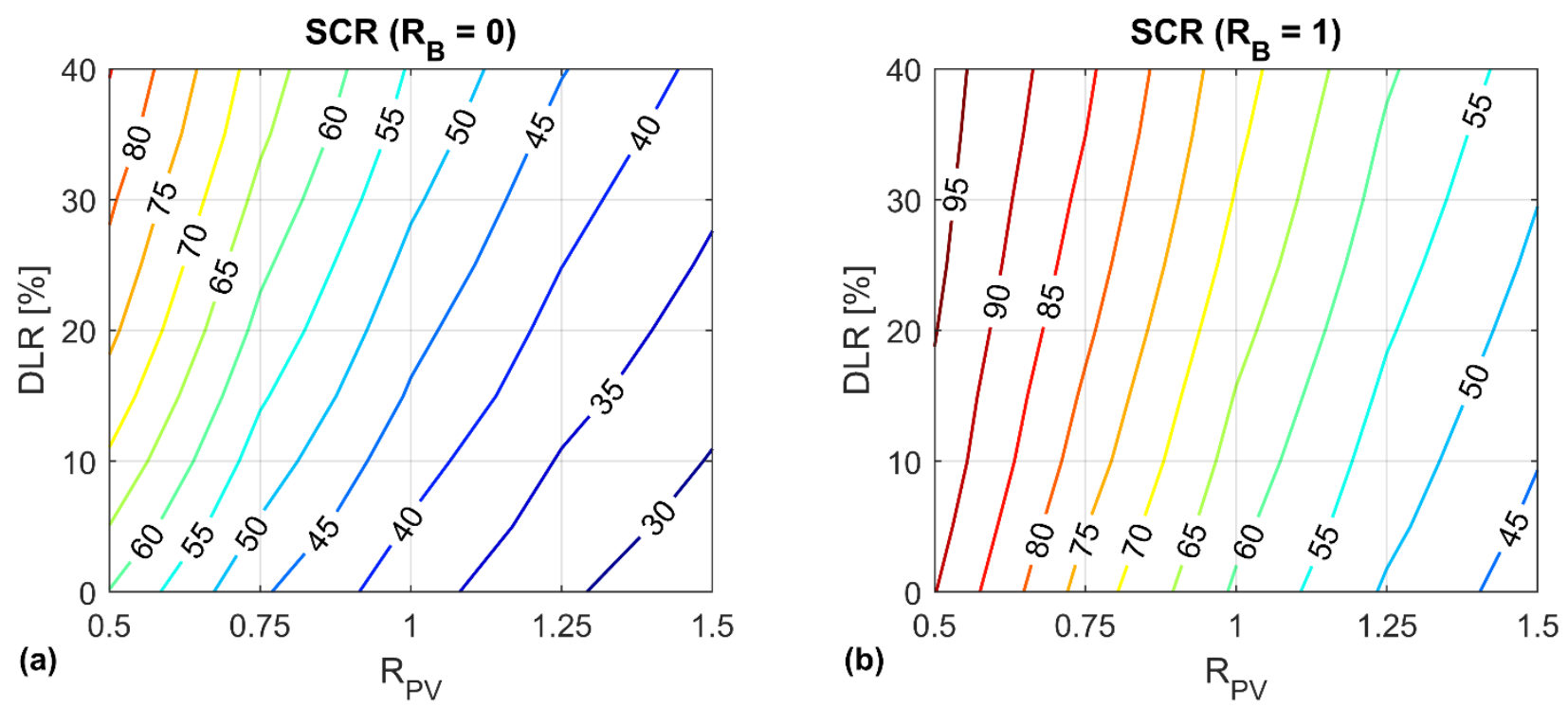

Figure 7 - Influence of deferrable loads ratio and PV size on the median SCR (a) without a battery bank ( $R_{B}$ $=0)$ and (b) with a battery bank $\left(R_{B}=1\right)$.

\subsection{Real case results: deterministic approach}

In this section, the results obtained by adopting a deterministic approach for managing weather forecast uncertainty are presented and discussed. Figure 8 shows the mean deviation of the SCR (indicated by $\Delta$ SCR) achieved in the ideal case with respect to that of the deterministic approach. The SCR is calculated as a function of the percentage of DLR and $\mathrm{R}_{\mathrm{B}}$, while weather forecast data delivered by WFS- 1 and WFS- 2 are used in Figures 8(a) and Figure 8(b), respectively. The median values of $\triangle$ SCR range between 0.5 and $4.5 \%$, with only minor differences between the two weather forecast services, although WFS-1 shows a higher accuracy and therefore lower $\triangle \mathrm{SCR}$ values. Figure 8 demonstrates that the deviation of the SCR increases when the 
percentage of deferrable loads rises. In fact, since deferrable loads are generally allocated during periods of expected high PV power production, the higher the amount of deferrable load, the more influential the accuracy of the weather forecast becomes. The rise in the battery size reduces the values of $\Delta \mathrm{SCR}$. In fact, the role of batteries is twofold: on one hand, the battery bank carries out time-shifting of the energy produced by the PV system and, at the same time, compensates for the deviations between the expected and actual PV productions. This fact suggests that the introduction of the battery bank, even with low values of $R_{B}$, makes it possible to improve the percentage of self-consumption of the home solar system.

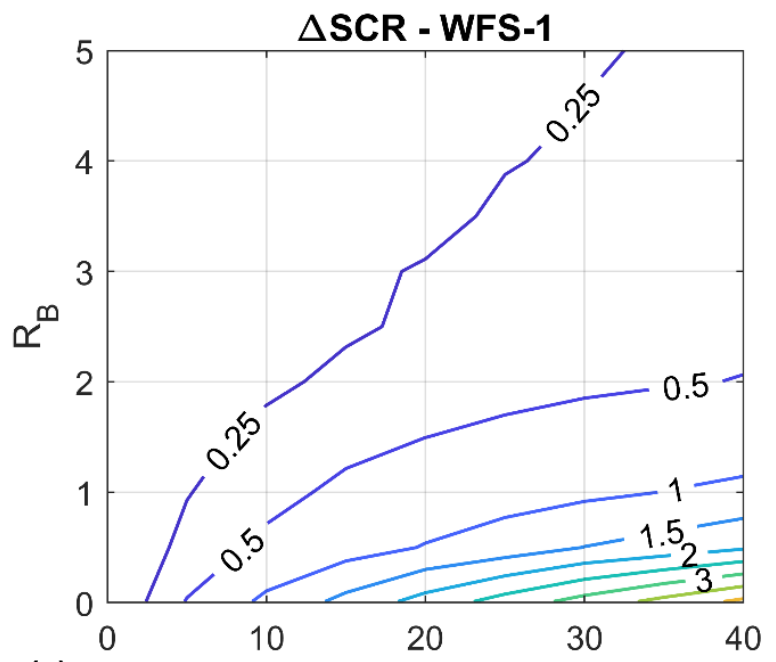

(a)

DLR [\%]

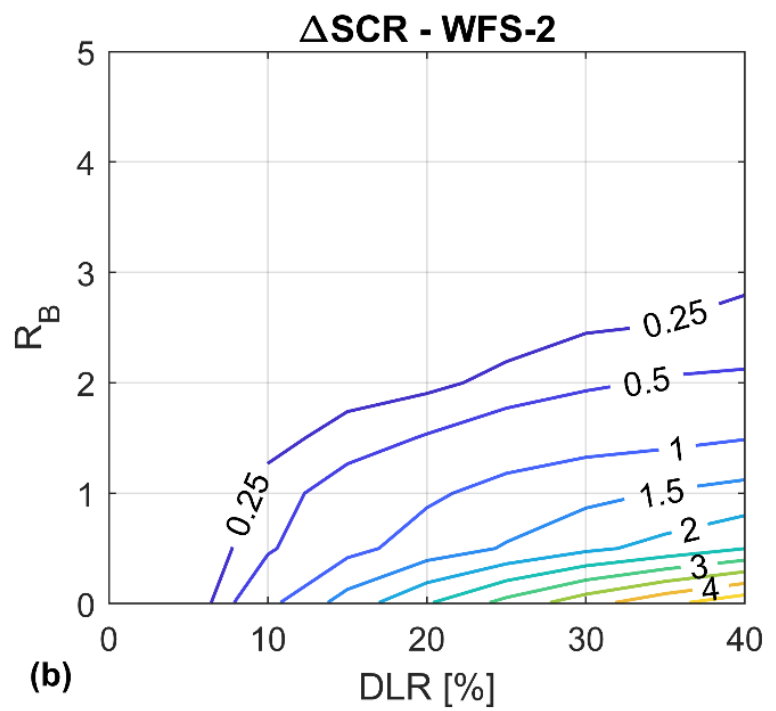

DLR [\%]

Figure 8 - Mean deviation of the SCR $(\triangle S C R)$ as a function of deferrable loads ratio and battery size $\left(R_{P V}=\right.$ 1).

\subsection{Real case results: stochastic approach}

As discussed in the previous section, by using the weather forecast data to optimize the energy selfconsumption, the most important deviation from the ideal approach occurs for high percentage values of deferrable loads and relatively low battery capacities. In this section, the capabilities of using a stochastic approach instead of a deterministic one in the optimization problem are investigated.

Figure 9 shows the SCR deviation from the ideal approach resulting from the adoption of a deterministic and a stochastic approach as a function of DLR and for different values of $R_{B}$. In particular, since the highest deviations are achieved for low values of $R_{B}$, three different values of $R_{B}$ are analysed: $R_{B}=0, R_{B}=0.5$, and $R_{B}=1$. The results obtained by adopting a deterministic approach are marked by " $D$ ” and are represented by solid lines, while those obtained with the stochastic approach are marked by "S" and are shown as dashed lines. The major benefits in adopting a stochastic approach arise when the inaccuracy of the weather forecast results in high risks. These cases are observed in the previous section for a high percentage of deferrable load and low relative battery capacity. Although the stochastic model is very simple, the introduction of the other two scenarios leads to more robust solutions and the effects of a possible variation of the PV production from the expected value are minimized. In other words, the allocation of deferrable loads remains optimal even with 
important deviations of the actual PV production curve compared to that calculated starting from the weather forecast. With the increase of the relative battery capacity, the accuracy of the solar radiation forecast becomes less relevant, as the batteries could suitably cover the possible mismatch between expected and actual PV energy production.

Therefore, the important decrease of the risk that occurs as the main reason for the deviation from an ideal approach is only due to the error in the daily available solar energy. In these conditions, the deterministic approach has already shown good performances, with a value of $\triangle \mathrm{SCR}$ lower than $2 \%$. Consequently, the advantages of adopting a stochastic approach are more and more negligible.
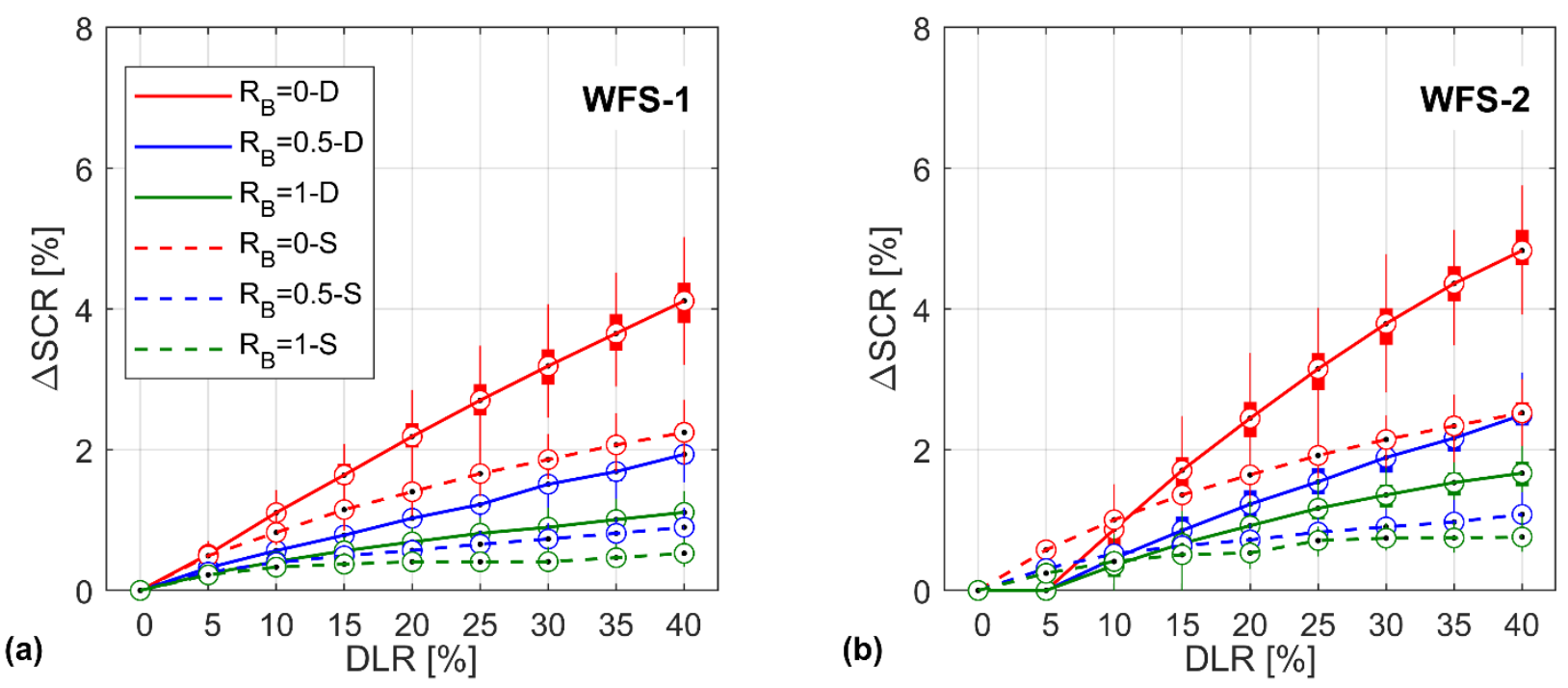

Figure 9 - Box plot of the $\triangle S C R$ achieved by adopting a deterministic (D) and a stochastic (S) approach as a function of the deferrable loads ratio for different battery size values when adopting (a) WFS-1 data and (b) WFS-2 data $\left(R_{P V}=1\right)$

\section{Preliminary economic analysis}

Finally, a preliminary economic analysis has been carried out in order to evaluate the profitability obtained with the improvement of the self-consumption in residential PV systems. A Benefit-Cost Ratio (BCR) is used as an economic performance index while no net-metering schemes or other incentives are considered for the self-consumed energy. The BCR is calculated as the ratio of the benefits achieved by the introduction of a home PV system and the corresponding costs:

$$
\mathrm{BCR}=\frac{\sum_{\mathrm{k}=1}^{\mathrm{PV}}\left[\mathrm{c}^{\mathrm{PUR}}\left(\mathrm{E}^{\mathrm{TL}}-\mathrm{E}^{\mathrm{PUR}}\right)+\mathrm{c}^{\mathrm{SEL}} \mathrm{E}^{\mathrm{SEL}}\right] \cdot(1+\mathrm{i})^{-\mathrm{k}}}{\mathrm{I}^{\mathrm{PV}} \mathrm{P}^{\mathrm{PV}, N O \mathrm{~N}_{n}} \mathrm{n}^{\mathrm{PV}}+\mathrm{I}^{\mathrm{B}} \mathrm{E}^{\mathrm{B}} \cdot\left[1+(1+\mathrm{i})^{-\mathrm{L}^{\mathrm{B}}}\right]+\sum_{\mathrm{k}=1}^{\mathrm{L}^{\mathrm{PV}}} \mathrm{c}^{\mathrm{O} \& \mathrm{M}} \cdot(1+\mathrm{i})^{-\mathrm{k}}}
$$

where the benefits are expressed in monetary terms by summing the savings coming from the lower electrical energy purchase from the grid and the revenues from the sale of the excess energy. The costs are the sum of 
capital and operating costs. With reference to the Italian electricity market [37], the electricity retail price for a typical domestic consumer and the minimum guaranteed feed-in price for PV systems are assumed as the purchasing and selling electricity costs, respectively. Obviously, all the benefits and costs are properly discounted by considering an interest rate and Table 3 reports the main assumptions.
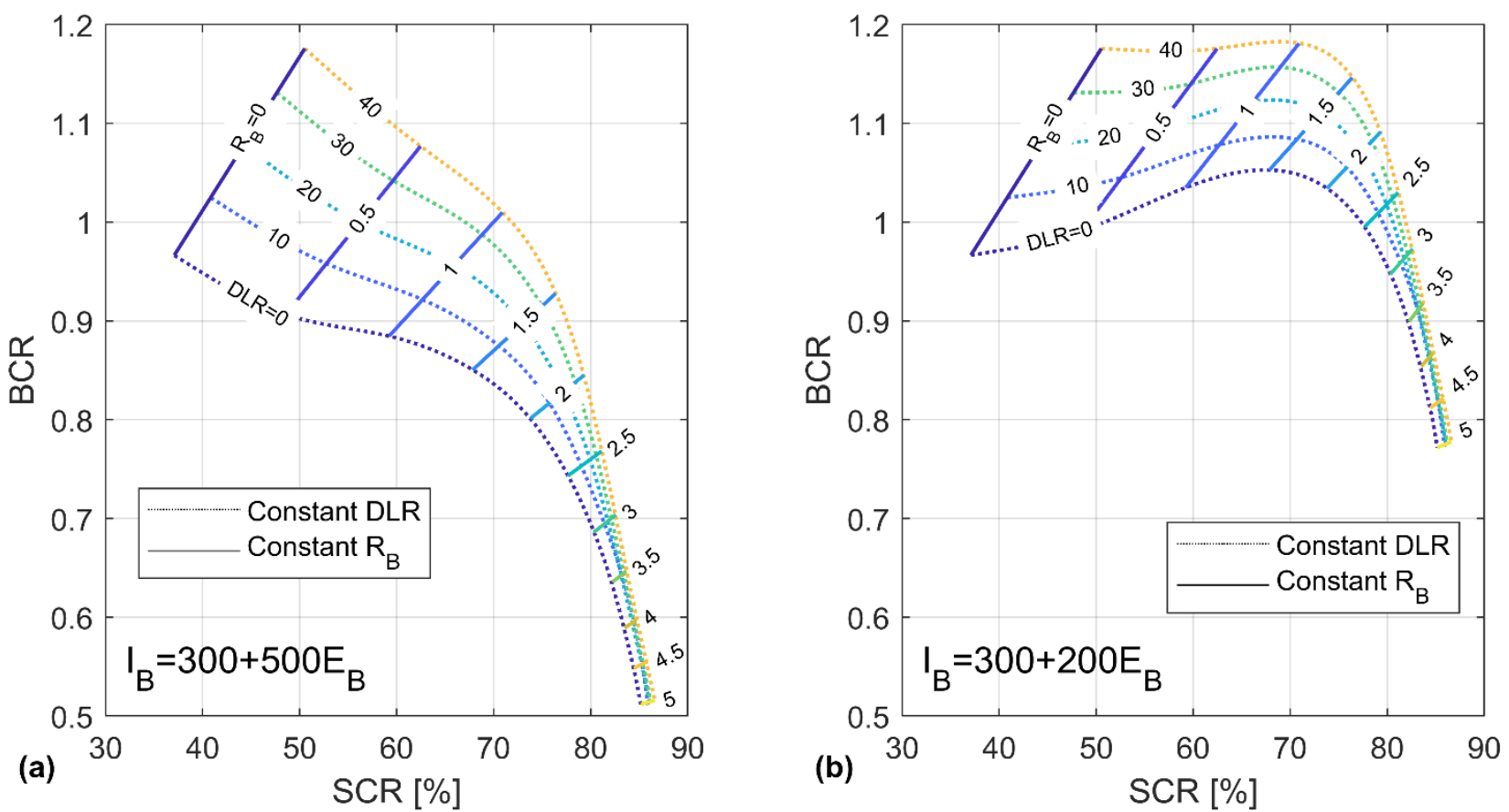

Figure 10 - Average benefit-cost ratio vs. self-consumption rate when adopting a deterministic approach.

Table 3 - Assumptions regarding cost parameters.

\begin{tabular}{lc}
\hline PV capital cost $\left(\mathrm{I}^{\mathrm{PV}}\right)$ & $1400 € / \mathrm{kW}$ \\
& $300+500 \mathrm{E}_{\mathrm{B}} €$ (current price) \\
Lithium-ion battery capital cost $\left(\mathrm{I}^{\mathrm{B}}\right)$ & $300+200 \mathrm{E}_{\mathrm{B}} €$ (future \\
scenario)
\end{tabular}


Figure 10 shows the relationship between the average BCR and the average SCR by applying a deterministic approach based on the WSF-1 data. In particular, Figure 10(a) shows the BCR-SCR curves by considering a battery capital cost in line with the current prices, while in Figure 10(b) a future scenario with an important reduction of the battery costs is considered. Firstly, by referring to the base case without considering any battery bank or deferrable load $\left(\mathrm{R}_{\mathrm{B}}=0\right.$ and DLR $\left.=0\right)$, the average BCR achieved is slightly lower than 1 (about 0.97), but about 50 household consumers already attains a BCR higher than 1 (that means an economic advantage to install PV system instead of purchasing energy from the grid). As mentioned, although the effect of batteries on the SCR is more significant than that of DLR, the latter incurs lower additional costs. Regardless of the considered battery cost, Figure 10 proves that the increase of the DLR always produces a positive effect on both the profitability and the energy independence of home solar systems, as demonstrated by the positive slope of the iso- $\mathrm{R}_{\mathrm{B}}$ curves. On the other hand, as shown in Figure 10(a), the highest BCR is achieved by $\mathrm{R}_{\mathrm{B}}=$ 0 , since the economic savings due to the introduction of batteries do not compensate for their initial cost. On the contrary, in a future scenario characterized by lower battery costs (Figure 10(b)), the BCR reaches the maximum values for a relative battery capacity in the range of 1-1.5 with a shift toward lower $R_{B}$ values for high values of DLR. In this case, the achieved SCR is around 70\%. Due to the asymptotic trend in the SCR already observed in the previous analysis, the economic benefits achieved with the increase of selfconsumption become more and more marginal with the rise in the battery capacity, and as a result the solution for high $\mathrm{R}_{\mathrm{B}}$ values is no longer cost-effective.

Finally, it is worth noting that the achieved results refer to the mean BCR and SCR values obtained for the 150 different load profiles considered here. Since the load profile shape has a strong influence on the selfconsumption rate, the economic performances could differ notably from each other. For this reason, three different load profiles were chosen as case studies (the main characteristics are reported in Table 4). All the cases are characterized by similar values of annual energy consumption and, with the assumption that $\mathrm{R}_{\mathrm{PV}}=$ 1, an installed PV power of $3 \mathrm{~kW}$. On the other hand, due to differences in household habits, the load profile shapes are remarkably different each other.

Table 4-Main characteristics of the three load profiles analysed

CASE A CASE B $\quad$ CASE C

$\begin{array}{lccc}\text { Annual energy consumption [MWh/yr] } & 4.25 & 4.20 & 4.26 \\ \text { Average daily peak load [kW] } & 0.83 \text { @ 8 p.m. } & 0.82 \text { @ 8 p.m. } & 0.69 \text { @ 15 p.m. } \\ \text { Installed PV power [kW] } & 3 & 3 & 3 \\ \text { Initial SCR ( } \mathrm{R}_{\mathrm{B}}=0 \text {; DLR = 0) } & 25.7 \% & 38.2 \% & 44.0 \% \\ \text { Initial BCR }\left(\mathrm{R}_{\mathrm{B}}=0 \text {; DLR }=0\right) & 0.79 & 0.98 & 1.07\end{array}$



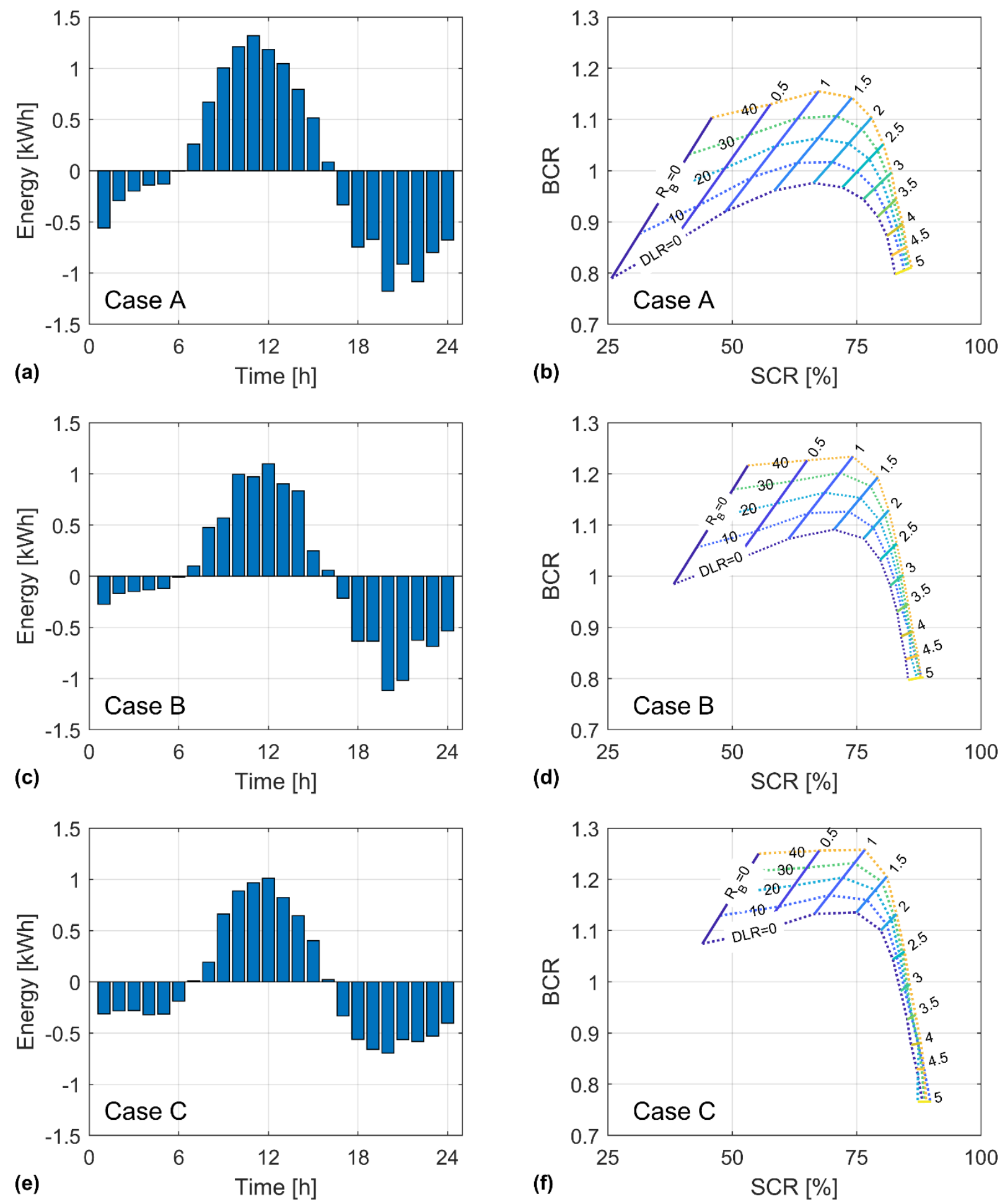

Figure 11 - Average daily surplus/deficit of energy and benefit-cost ratio vs. self-consumption rate for three different case studies.

Figure 11 shows the average daily surplus/deficit of energy (calculated as the difference between the PV power production and the load demand) and the corresponding BCR-SCR correlation for the three cases by considering the future scenario for the calculation of the battery price. The first case (called case A in Figure 11(a)) is characterized by a high load demand during the evening and a very low energy demand during the 
sunshine hours. This causes a frequent mismatch between on-site production and demand of energy, attaining to a low SCR without the introduction of a battery bank or the adoption of a deferring load strategy. The second case (Case B in Figure 11(c)) is characterized by a lower load demand during the evening and higher load request during the morning, resulting in a rise of the base SCR and an initial BCR almost equal to 1. In the third case (Case C in Figure 11(e)), due to the high load demand during the sunshine hours, a high percentage of the energy produced by PV supplies the demanded load directly, achieving a relatively high SCR and BCR>1 even without considering either energy storage or deferment of loads. As expected, the economic profitability is significantly dependent on the considered case and improves with the increase of the initial SCR. On the other hand, the maximum BCR is obtained with a self-consumption rate of around $70-75 \%$ for all the three case, highlighting the fact that this optimal value does not depend on the considered load profile. However, the relative battery capacity required to reach this target varies with the considered load profile, with the highest value of $\mathrm{R}_{\mathrm{B}}$ being demanded in case A, as shown in Figure 11(b). In fact, this case requires a larger energy time-shift and therefore this household largely benefits from the introduction of an energy storage system (the relative improvement in BCR from the initial value and the maximum one is around $25 \%$ in case of DLR=0), even if high initial costs are required. On the other hand, case C (Figure 11(f)) attains the lowest BCR increment (lower than 10\% in case of DLR=0) but the optimal relative battery capacity is lower than that of the other cases, achieving the best economic performance.

\section{Conclusions}

The aim of this study was to evaluate the self-consumption rate that Italian household prosumers could reach by solving suitable optimization problems based on the use of weather forecast data. In order to investigate the effect of the weather forecast uncertainty on the energy management of home PV systems equipped with a battery bank, 150 Italian load profiles have been considered. The self-consumption rate of residential prosumers has been evaluated by solving of a proper optimization problem that uses a stochastic approach for the prediction of the PV daily power production starting from the weather forecast data. The results achieved by using this stochastic approach are compared with those obtained by an ideal approach and with those obtained by a deterministic approach.

The analysis shows that the reference self-consumption rate, which is achieved by using the ideal approach, varies in the range of $40-80 \%$ in function of the percentage of deferrable loads, battery bank size, and PV size. The comparison of the ideal and deterministic approaches shows that the uncertainty of weather forecast data reduces the achievable self-consumption rate by about $0.5-4.5 \%$. The adoption of a stochastic approach makes it possible to improve the self-consumption rate of households especially in the case of high uncertainties of weather forecast data and high percentage of deferrable load. Finally, a preliminary economic analysis was carried out, highlighting the cost-ineffectiveness of the adoption of a battery bank by considering the current battery price levels. In this case, the SCR obtained is in the range of 35-50\%. A reduction of the battery price is therefore required to make the introduction of a battery bank economically attractive.

It is worth nothing that uncertainty in the load demand profile is another important uncertainty factor. The proposed optimization problem can be suitably modified in order to take into account this additional 
uncertainty factor in the evaluation of the self-consumption rate of households. However, the characterization of this uncertainty remains an open issue.

\section{Acknowledgment}

Authors would like to thank Euro Cogliani for his helpful advice on weather forecast algorithms and the valuable sharing of weather forecast and measured data in ENEA Casaccia.

\section{References}

[1] International Energy Agency. World Energy Outlook 2016. IEA Publications; 2016.

[2] International Energy Agency. World Energy Outlook 2012. IEA Publications; 2012.

[3] Gestore dei Servizi Energetici. Rapporto statistico - Energia da fonti rinnovabili in Italia, Anno 2015. 2017.

[4] International Energy Agency. Renewables Information 2016. IEA Publications; 2016.

[5] Brusco G, Burgio A, Menniti D, Pinnarelli A, Sorrentino N. The economic viability of a feed-in tariff scheme that solely rewards self-consumption to promote the use of integrated photovoltaic battery systems. Appl Energy 2016;183:1075-85. doi:10.1016/j.apenergy.2016.09.004.

[6] Luthander R, Widén J, Nilsson D, Palm J. Photovoltaic self-consumption in buildings: A review. Appl Energy 2015;142:80-94. doi:10.1016/j.apenergy.2014.12.028.

[7] Shivashankar S, Mekhilef S, Mokhlis H, Karimi M. Mitigating methods of power fluctuation of photovoltaic (PV) sources - A review. Renew Sustain Energy Rev 2016;59:1170-84. doi:10.1016/j.rser.2016.01.059.

[8] Hoppmann J, Volland J, Schmidt TS, Hoffmann VH. The economic viability of battery storage for residential solar photovoltaic systems - A review and a simulation model. Renew Sustain Energy Rev 2014;39:1101-18. doi:10.1016/j.rser.2014.07.068.

[9] Merei G, Moshövel J, Magnor D, Sauer DU. Optimization of self-consumption and techno-economic analysis of PV-battery systems in commercial applications. Appl Energy 2016;168:171-8. doi:10.1016/j.apenergy.2016.01.083.

[10] Luthander R, Widén J, Munkhammar J, Lingfors D. Self-consumption enhancement and peak shaving of residential photovoltaics using storage and curtailment. Energy 2016;112:221-31. doi:10.1016/j.energy.2016.06.039.

[11] de Oliveira e Silva G, Hendrick P. Lead-acid batteries coupled with photovoltaics for increased electricity self-sufficiency in households. Appl Energy 2016;178:856-67. doi:10.1016/j.apenergy.2016.06.003. 
[12] Linssen J, Stenzel P, Fleer J. Techno-economic analysis of photovoltaic battery systems and the influence of different consumer load profiles. Appl Energy 2017;185:2019-25. doi:10.1016/j.apenergy.2015.11.088.

[13] Quoilin S, Kavvadias K, Mercier A, Pappone I, Zucker A. Quantifying self-consumption linked to solar home battery systems: Statistical analysis and economic assessment. Appl Energy 2016;182:58-67. doi:10.1016/j.apenergy.2016.08.077.

[14] Nyholm E, Goop J, Odenberger M, Johnsson F. Solar photovoltaic-battery systems in Swedish households - Self-consumption and self-sufficiency. Appl Energy 2016;183:148-59. doi:10.1016/j.apenergy.2016.08.172.

[15] Lund PD, Lindgren J, Mikkola J, Salpakari J. Review of energy system flexibility measures to enable high levels of variable renewable electricity. Renew Sustain Energy Rev 2015;45:785-807. doi:10.1016/j.rser.2015.01.057.

[16] Drysdale B, Wu J, Jenkins N. Flexible demand in the GB domestic electricity sector in 2030. Appl Energy 2015;139:281-90. doi:10.1016/j.apenergy.2014.11.013.

[17] Widén J. Improved photovoltaic self-consumption with appliance scheduling in 200 single-family buildings. Appl Energy 2014;126:199-212. doi:10.1016/j.apenergy.2014.04.008.

[18] Castillo-Cagigal M, Caamaño-Martín E, Matallanas E, Masa-Bote D, Gutiérrez A, Monasterio-Huelin F, et al. PV self-consumption optimization with storage and Active DSM for the residential sector. Sol Energy 2011;85:2338-48. doi:10.1016/j.solener.2011.06.028.

[19] Castillo-Cagigal M, Gutiérrez A, Monasterio-Huelin F, Caamaño-Martín E, Masa D, Jiménez-Leube J. A semi-distributed electric demand-side management system with PV generation for self-consumption enhancement. Energy Convers Manag 2011;52:2659-66. doi:10.1016/j.enconman.2011.01.017.

[20] Femia N, Toledo D, Zamboni W. Storage unit and load management in photovoltaic inverters for residential application. IECON 2013 - 39th Annu. Conf. IEEE Ind. Electron. Soc., Vienna, Austria: IEEE; 2013, p. 6800-5. doi:10.1109/IECON.2013.6700258.

[21] Widén J, Munkhammar J. Evaluating the benefits of a solar home energy management system : impacts on photovoltaic power production value and grid interaction. ECEEE Summer Study Proc., Toulon/Hyères (France): 2013, p. 1223-33.

[22] Inman RH, Pedro HTC, Coimbra CFM. Solar forecasting methods for renewable energy integration. Prog Energy Combust Sci 2013;39:535-76. doi:10.1016/j.pecs.2013.06.002.

[23] Marinelli M, Sossan F, Costanzo GT, Bindner HW. Testing of a Predictive Control Strategy for Balancing Renewable Sources in a Microgrid. IEEE Trans Sustain Energy 2014;5:1426-33. doi:10.1109/TSTE.2013.2294194. 
[24] Petersen S, Bundgaard KW. The effect of weather forecast uncertainty on a predictive control concept for building systems operation. Appl Energy 2014;116:311-21. doi:10.1016/j.apenergy.2013.11.060.

[25] Wang X, Palazoglu A, El-Farra NH. Operational optimization and demand response of hybrid renewable energy systems. Appl Energy 2015;143:324-35. doi:10.1016/j.apenergy.2015.01.004.

[26] Masa-Bote D, Castillo-Cagigal M, Matallanas E, Caamaño-Martín E, Gutiérrez A, Monasterio-Huelín F, et al. Improving photovoltaics grid integration through short time forecasting and self-consumption. Appl Energy 2014;125:103-13. doi:10.1016/j.apenergy.2014.03.045.

[27] REMODECE Homepage n.d. http://remodece.isr.uc.pt/ (accessed November 16, 2017).

[28] Solar Web Services by Meteotest n.d. https://solarwebservices.ch/ (accessed November 15, 2017).

[29] Cogliani E. The role of the direct normal irradiance (DNI) forecasting in the operation of solar concentrating plants. Energy Procedia 2013;49:1612-21. doi:10.1016/j.egypro.2014.03.170.

[30] Zhang J, Hodge B-M, Florita A, Lu S, Hamann HF, Banunarayanan V. Metrics for Evaluating the Accuracy of Solar Power Forecasting. 3rd Int. Work. Integr. Sol. Power into Power Syst., London, England: 2013, p. 1-10.

[31] Duffie J a., Beckman W a., Worek WM. Solar Engineering of Thermal Processes, 4nd ed. vol. 116. 2013. doi:10.1115/1.2930068.

[32] ABB. PVI-10.0/12.5-TL-OUTD Datasheet 2014;2014:2. http://new.abb.com/power-convertersinverters/solar/string/three-phase/pvi-10-0kw-12-5kw (accessed January 28, 2016).

[33] SolarWorld. SW $250 \quad$ - $260 \quad$ poly $\quad$ - $\quad$ DataSheet 2016. http://www.solarworld.de/fileadmin/downloads_new/produkt/sunmodule/datenblaetter/en/poly/poly_ 250-260_en.pdf (accessed January 28, 2016).

[34] Marion B, Adelstein J, Boyle K, Hayden H, Hammond B, Fletcher T, et al. Performance parameters for grid-connected PV systems. Conf. Rec. Thirty-first IEEE Photovolt. Spec. Conf. 2005., IEEE; n.d., p. 1601-6. doi:10.1109/PVSC.2005.1488451.

[35] Battke B, Schmidt TS, Grosspietsch D, Hoffmann VH. A review and probabilistic model of lifecycle costs of stationary batteries in multiple applications. Renew Sustain Energy Rev 2013;25:240-50. doi:10.1016/j.rser.2013.04.023.

[36] Velarde P, Valverde L, Maestre JM, Ocampo-Martinez C, Bordons C. On the comparison of stochastic model predictive control strategies applied to a hydrogen-based microgrid. J Power Sources 2017;343:161-73. doi:10.1016/j.jpowsour.2017.01.015.

[37] Autorità per l'energia elettrica il gas e il sistema idrico - Prezzi al kWh per cliente tipo servito in maggior tutela aggiornamento trimestrale n.d. 
http://www.autorita.energia.it/it/elettricita/prezzirif.htm (accessed July 19, 2017). 